\title{
Triple Band X Shape Microstrip Patch Antenna for Ku/K Band Applications
}

\author{
M. Samsuzzaman ${ }^{1,2}$, M. T. Islam ${ }^{2} \&$ J. S. Mandeep ${ }^{2}$ \\ ${ }^{1}$ Faculty of Engineering and Built Environment, Universiti Kebangsaan Malaysia, Malaysia \\ ${ }^{2}$ Institute of Space Science (ANGKASA), Universiti Kebangsaan Malaysia, Malaysia \\ Correspondence: M. Samsuzzaman, Faculty of Engineering and Built Environment; Institute of Space Science \\ (ANGKASA), Universiti Kebangsaan Malaysia, Malaysia. E-mail: sobuzcse@eng.ukm.my
}

Received: April 19, $2013 \quad$ Accepted: July 10, $2013 \quad$ Online Published: July 19, 2013

doi:10.5539/mas.v7n8p70 URL: http://dx.doi.org/10.5539/mas.v7n8p70

\begin{abstract}
In this article, electrically small, triple band, triple frequency $\mathrm{X}$ shaped patch antenna is presented. The proposed $\mathrm{X}$ shape patch antenna consists of five rectangular slots which produces dual band operation for Ku band applications and another one for $\mathrm{K}$ band applications. In order to achieve multiband operation from conventional rectangular slot, it is introduced three equilateral triangle slots in left, right and upper edge respectively, and two small triangular slots are protruding both sides of the feed line. By increasing the number of steps, the antenna's operating bandwidth, with return loss less than $-10 \mathrm{~dB}$, covers the frequency ranges from $15.104 \mathrm{GHz}$ to 15.632 $\mathrm{GHz}, 17.336$ to $17.912 \mathrm{GHz}$ which is suitable for $\mathrm{Ku}$ band applications and 18.476 to $19.28 \mathrm{GHz}$ which is suitable for $\mathrm{K}$ band applications. The proposed antenna has also achieved symmetric and almost steady radiation patterns and peak gains of $4.80 \mathrm{dBi}, 6.42 \mathrm{dBi}$ and $3.91 \mathrm{dBi}$ at these operating bands.
\end{abstract}

Keywords: $\mathrm{X}$ shape, multiband, patch antenna, triangular slot, $\mathrm{Ku} / \mathrm{K}$ band

\section{Introduction}

Basically each antenna operates at a single frequency but with the rapid development of modern wireless communication system and their applications, wider bandwidth and multifrequency are required, where a different antenna for different applications. On the other hand, there is a great demand for wireless devices that are lightweight, small, attractive and multitasking. Currently, in radar and space satellite communication application, microstrip patch antennas have great demand due to their low profile, mechanical robustness, compatible with MMIC designs, relatively compact and light in weight and double frequency operation (Balanis, 2012). They are easy and low-cost to manufacture and can be conformable in planar and non-planar planes. But, unfortunately they have some limitations and disadvantageous such as relatively low efficiency and low power, spurious feed radiation, narrow frequency bandwidth and relatively high level of cross polarization radiation (Garg, 2001). To overcome these limitations and disadvantageous, researchers have been proposed and investigated many techniques such as slotted patch antennas, microstrip patch antennas on an electrically thick substrate, probe feed stack antenna and the use of various feeding and impedance matching techniques, the use of multiple resonators (Alam, Islam, \& Misran, 2012; Azim, Islam, Mandeep, \& Mobashsher, 2012; Chen \& Yung, 2009; Habib Ullah \& Islam, 2012; Islam, Mobashsher, \& Misran, 2010; Samsuzzaman, Islam, \& Mandeep, 2012; Samsuzzamana, Islamb, \& Faruqueb, 2013; Shakib, Islam, \& Misran, 2010; Tiang, Islam, Misran, \& Mandeep, 2011). In this paper, an effort is performed to design a triangular fractal antenna of effective radiation, intact size and multiband properties. It can be seen that greater demand is created by means of quick growth of wireless communications and electronics for wireless devices that can obey different rules at different standards. It also the paved the way for wide usage of mobile phones in modern society resulting in mounting concerns surrounding its harmful radiation (Faruque, Islam, \& Misran, 2010, 2011, 2012). Presently, wider bandwidth is required for the increasing demand of modern wireless communication system applications. Generally each antenna performs its function at a single frequency, so different antennas require for different applications that will cause a restricted place and space problems. Considerable research effort has gone into the design of multiband antennas. A $41 \mathrm{~mm} \times 14 \mathrm{~mm}$ slotted multiband antenna was designed which had three frequency bands centered at $0.9 \mathrm{GHz}, 1.8 \mathrm{GHz}$ and $5.2 \mathrm{GHz}$ (Rao \& Geyi, 2009). A $38 \mathrm{~mm} \times 3 \mathrm{~mm}$ planar multiband antenna was proposed for GPS, DCS, and WLAN applications (Eldewiny, Shams, \& Allam, 2010). A 
planar dual L-shaped antenna $30.5 \mathrm{~mm} \times 21.5 \mathrm{~mm}$ operating in the $1.569 \mathrm{GHz}-1.585 \mathrm{GHz}$ and $1.850 \mathrm{GHz}-1.990$ $\mathrm{GHz}$ bands has been pro-posed (Chen, Ganjara, \& Chen, 2002). A $2.4 \mathrm{GHz}$ and $5.8 \mathrm{GHz}$ dual band antenna were proposed for the ISM band using a backed microstrip line (Pongchompoo, Santitewagul, \& Eungdamrong, 2009) $30 \mathrm{~mm} \times 20 \mathrm{~mm}$ overall on an FR4 substrate and achieved a maximum gain of $4 \mathrm{dBi}$. However, the reported antennas were either larger, had a narrow bandwidth, low gain or were less efficient. There is still room to explore miniature antennas with wider bandwidth, and higher gain and efficiency.

In this paper, a tripple triangular slot $\mathrm{X}$ shaped multiband patch antenna is designed with bandwidths of 528 $\mathrm{MHz}, 576 \mathrm{MHz}$ and $804 \mathrm{MHz}$ and $4.80 \mathrm{dBi}, 6.72 \mathrm{dBi}$ and $3.91 \mathrm{dBi}$ peak gain of these particular operating bands respectively.

\section{Antenna Design Architecture and Optimization}

The configuration of the proposed patch $\mathrm{X}$ shaped patch antenna is shown in Figure 1. The geometrical parameters of the proposed shape antenna are obtained by using Ansoft's 3D full wave electromagnetic simulator HFSS which is based on Finite Element Method (FIT). It is printed on Rogers RT/Duroid 6010 composite material substrates of thickness $\mathrm{h}=1.905$, relative permittivity $\varepsilon_{\mathrm{r}}=10.2$, loss tangent $\tan \delta=0.0023$. This material features ease of fabrication and stability in use. They have tight dielectric constant and thickness control, low moisture absorption, and good thermal mechanical stability. About $50 \mathrm{ohm}$ a microstrip feed line etched on the down side of the radiating patched with dimensions of $L_{f}$ and $W_{f}$. The antenna has a compact structure and total dimension is about $9.50 \mathrm{~mm} \times 7 . \times 1.905 \mathrm{~mm}$ but radiating dimension is $8.5 \mathrm{~mm} \times 7.96 \times$ $1.905 \mathrm{~mm}$ and the ground plane area is $2.5 \mathrm{~mm} \times 7.96 \mathrm{~mm}$. Actually the radiating patch is a rectangular structure with five triangular slots. The area and the position of these five triangular slots are responsible for varying resonance frequency. Each triangular slot has two arms equal and third arm's length is twice than others. Because of these three triangular slots, current lines are changed. The current is to flow around the patch. So the effective length of the current lines becomes longer and the antenna size becomes miniature. In order to achieve good impedance matching and symmetrical excitement, proposed shaped antennas feeding is selected to the centered at the midpoint of the $y$ axis length of the antenna. Equilateral slots are applied to achieve the multi band performances with sufficient $-10 \mathrm{~dB}$ impedance bandwidth. In Table 1, all the exhaustive parameters of the proposed shape antenna are summarized.

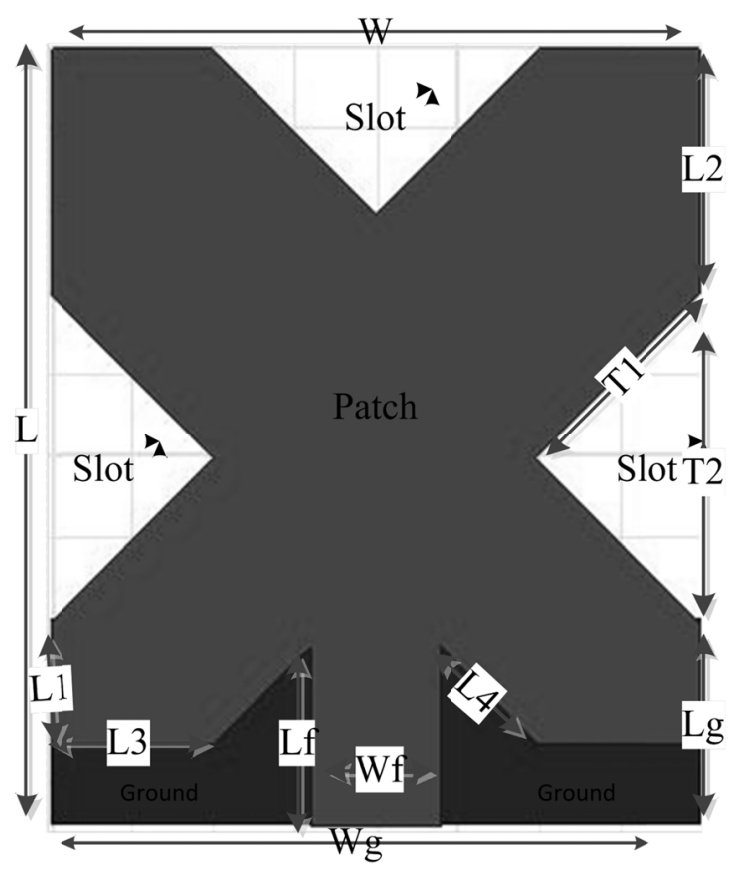

(a)

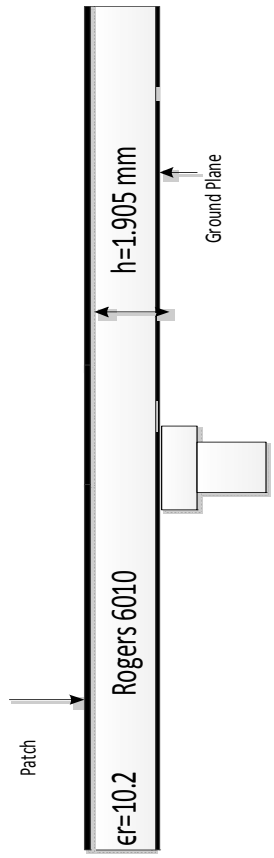

(b)

Figure 1. Proposed antenna geometric layout (a) Front view (b) Side view 
Table 1. Parameters of the proposed antenna

\begin{tabular}{cccc}
\hline Parameter & Value $(\mathbf{m m})$ & Parameter & Value $(\mathbf{m m})$ \\
\hline $\mathbf{L}$ & 9.5 & $\mathrm{~L} 2$ & 3 \\
$\mathbf{W}$ & 7.96 & $\mathrm{~L} 3$ & 1.98 \\
$\mathbf{L g}$ & 2.5 & $\mathrm{~L} 4$ & 1.69 \\
$\mathbf{W g}$ & 7.96 & $\mathrm{~T}_{1}$ & 2.82 \\
$\mathbf{L}$ & 2.2 & $\mathrm{~T}_{2}$ & 4 \\
$\mathbf{W f}$ & 1.6 & $\mathrm{~h}$ & 1.905 \\
$\mathbf{L 1}$ & 1.5 & & \\
\hline
\end{tabular}

Figure 2 shows the effects of the no. of triangular slots in the conventional rectangular shape to five triangular slot patches. It is clearly said that the proposed antenna reflection coefficient is better than others. The proposed shaped which is shown in Figure 1(b) and which is obtained by cutting five triangular slots in the conventional rectangular slots. In Figures 3, 4 and 5, here the authors have investigated the different values of $L 1, L 2$ and $L 3$. From these figures, it could be easily observed that the $L 1=1.5 \mathrm{~mm}, L 2=3 \mathrm{~mm}$ and $L 3=1.98 \mathrm{~mm}$ are the best parameter for good impedance bandwidth and reflection coefficient.

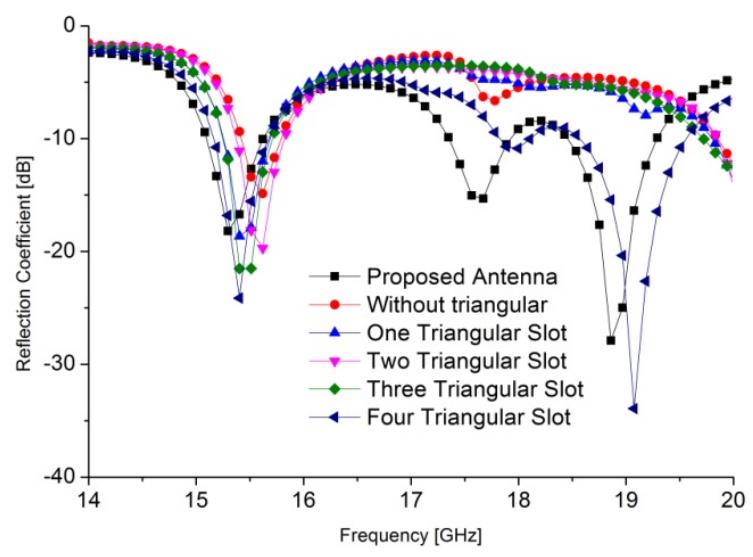

Figure 2. Reflection coefficients for values of L1

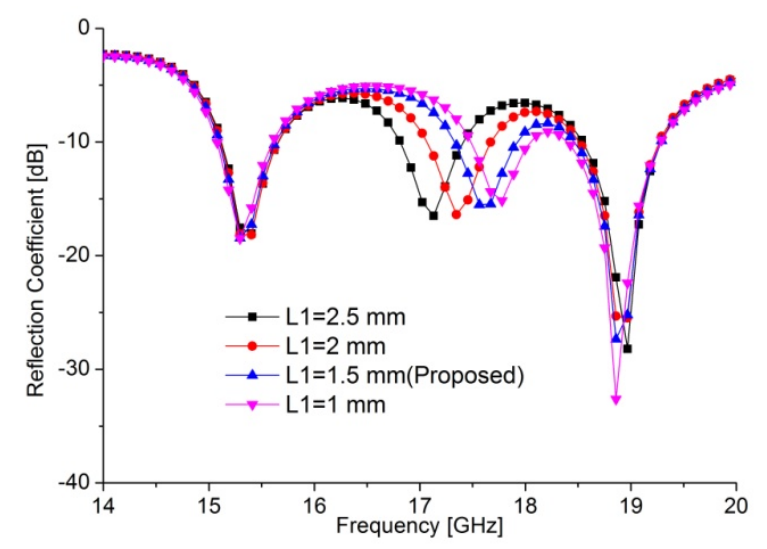

Figure 3. Reflection coefficients for different different slots 


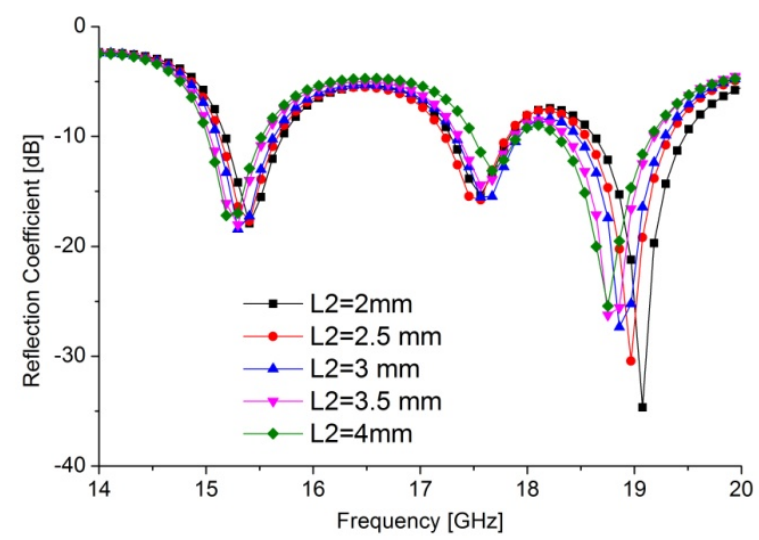

Figure 4. Reflection coefficients for different values of L3

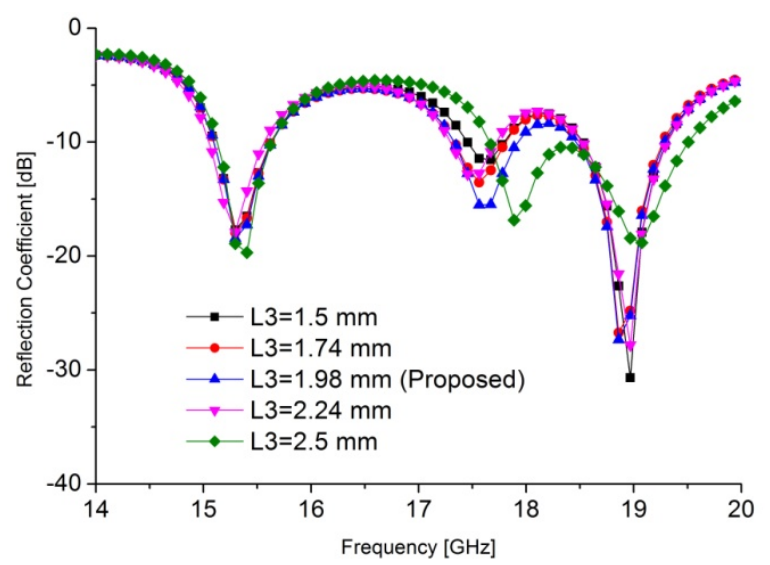

Figure 5. Reflection coefficients for different values of L2

\section{Results and Discussions}

The different characteristics of the proposed shape antenna are investigated and optimized by commercially available finite element based software HFSS. The VSWR and peak gain of the final shape are shown in Figure 6 and Figure 7. In that Figure, the first fractional bandwidth is $6.03 \%$ from $15.104-15.632 \mathrm{GHz}$, the second one is $6.93 \%$ from $17.336-17.912 \mathrm{GHz}$, and third one is $9.59 \%$ from $18.476-19.280 \mathrm{GHz}$. The resonance frequencies of this region are $15.33 \mathrm{GHz}, 17.61 \mathrm{GHz}$ and $18.90 \mathrm{GHz}$ where maximum return loss $19.20 \mathrm{~dB}, 16.045 \mathrm{~dB}$ and $45.47 \mathrm{~dB}$ respectively.

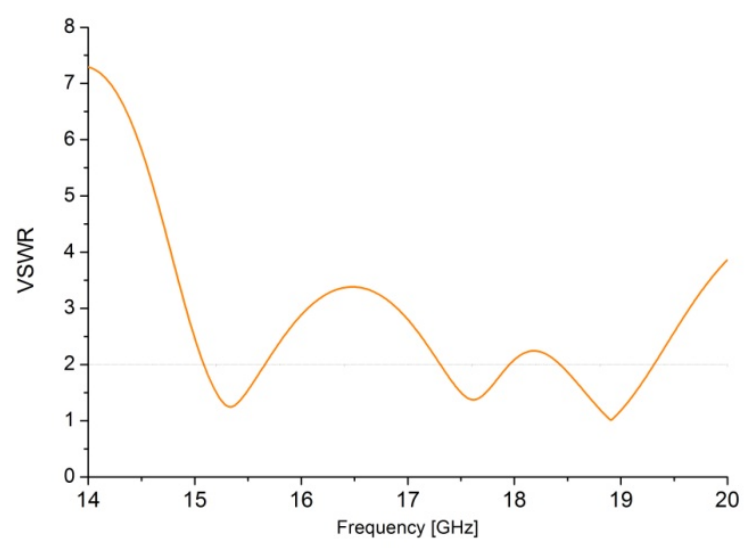

Figure 6. VSWR with frequecny 


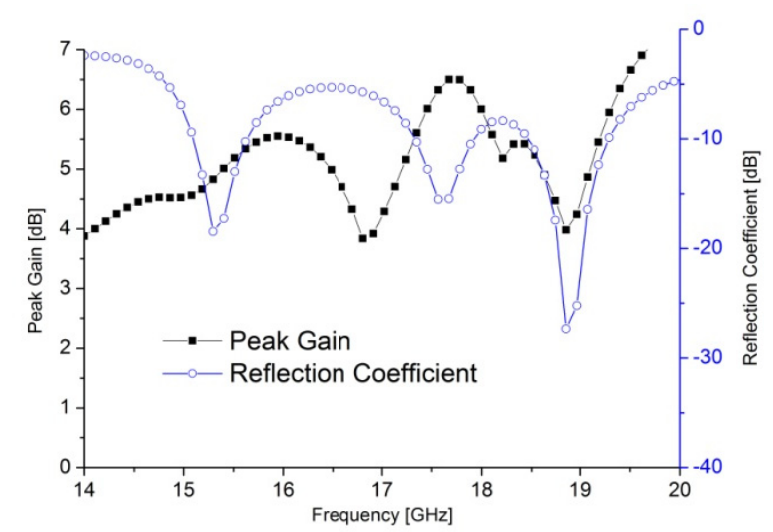

Figure 7. Simulated return loss and peak gain with frequency

Again as shown in Figure 7, the average peak gain of the proposed antenna for first band is almost $4.80 \mathrm{~dB}$, for second band is $6.42 \mathrm{~dB}$ and for third band is about $3.91 \mathrm{~dB}$. It is marked from the return loss and the gain curve that the proposed shape antenna is utterly capable of transmitting and receiving in the desired Ku band of 15.33 $\mathrm{GHz}$ and $17.61 \mathrm{GHz}$ respectively and $\mathrm{K}$ band of $18.90 \mathrm{GHz}$ with a better peak gain characteristic than others. The radiation pattern in the azimuth plane (E plane) and elevation plane (H-plane) of the proposed antenna at different resonance frequency is depicted in Figure 8. The co-polarization is low compared to cross polarization and also symmetric and omnidirectional.
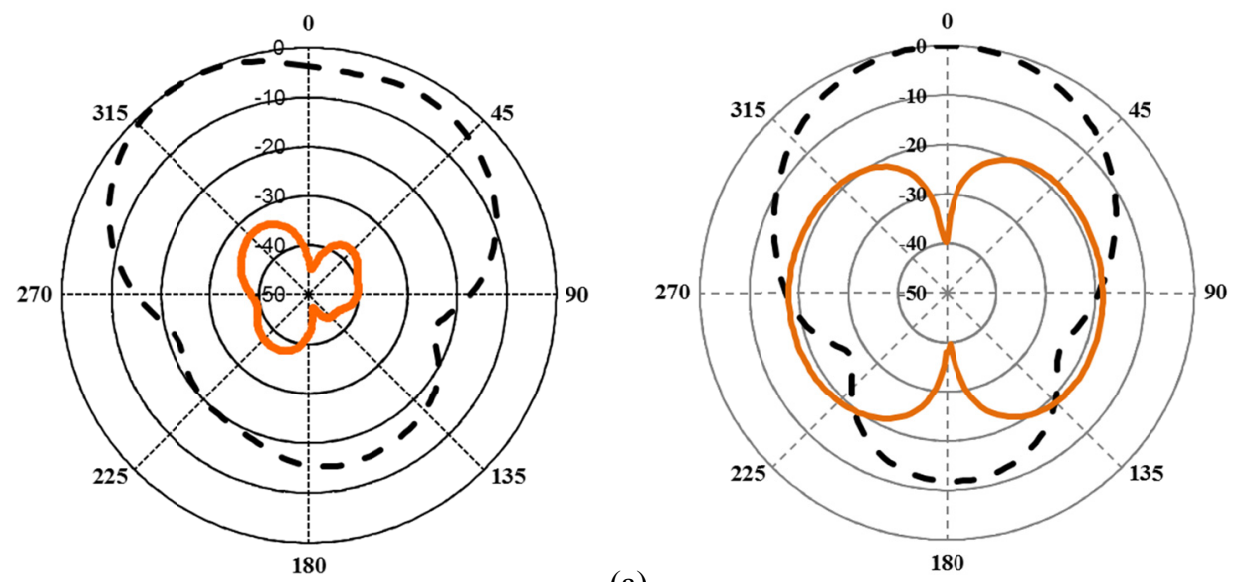

(a)
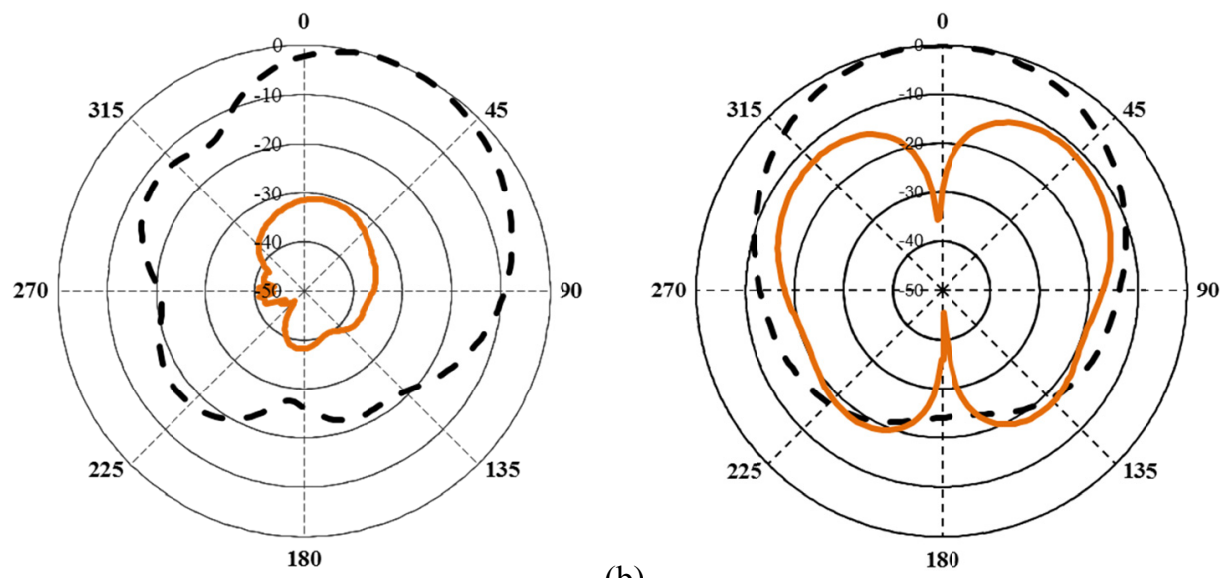

(b) 


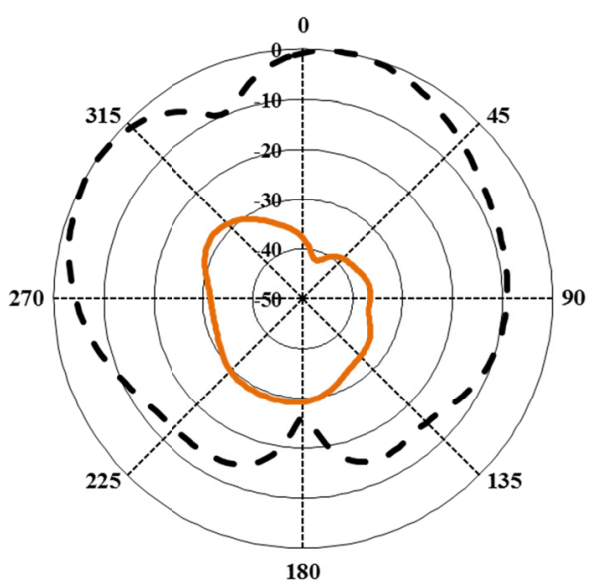

(c)

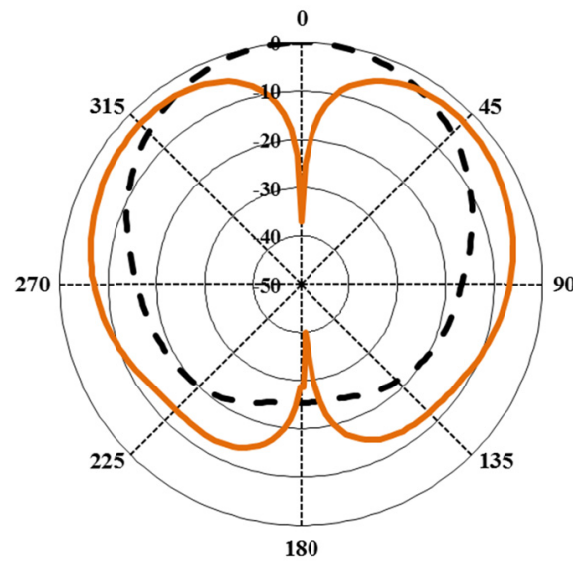

H Plane

E plane

Cross polarization

Co polarization

Figure 8. Radiation pattern of the proposed shape antenna at a) $15.33 \mathrm{GHz}$ b) $17.61 \mathrm{GHz}$ and c) $18.90 \mathrm{GHz}$

From the E plane, broad beam width is identified in the main beam of co-polarized. From the radiation pattern, it can be easily said that the designed antenna produces omnidirectional radiation and almost stable radiation pattern throughout the whole operating band with low cross polarization.

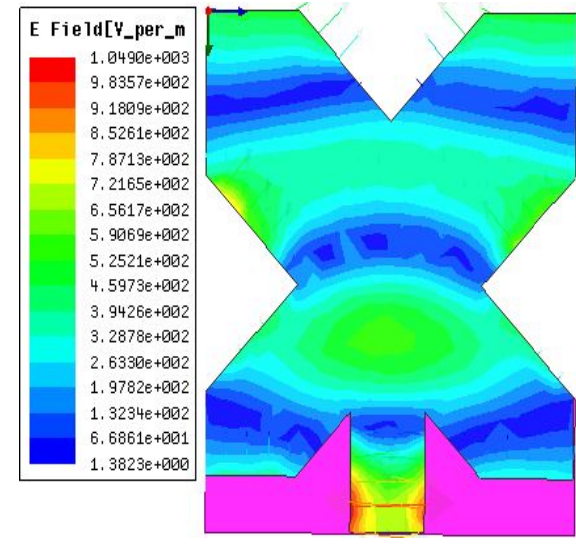

(a)

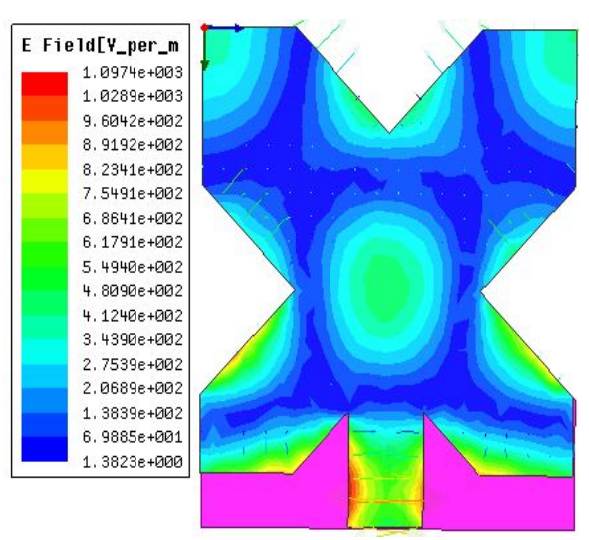

(b)

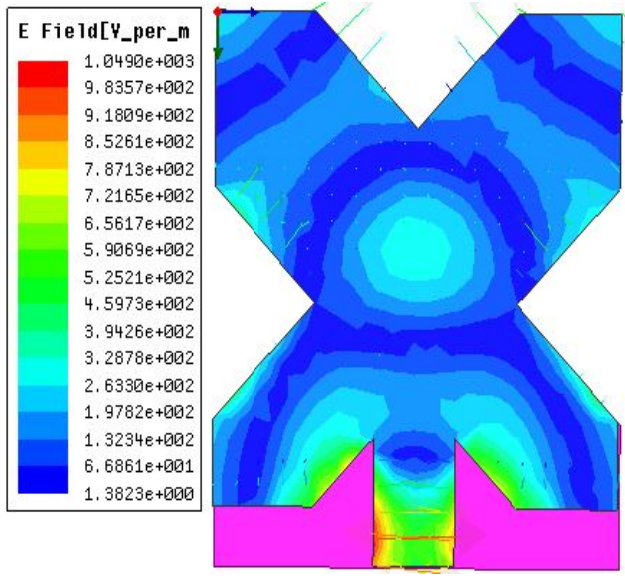

(c)

Figure 9. Current distribution at a) $15.33 \mathrm{GHz}$ b) $17.61 \mathrm{GHz}$ c) $18.90 \mathrm{GHz}$ 
Figure 9 depicts the current distribution on the patch at resonance frequency $15.33 \mathrm{GHz}, 17.61 \mathrm{GHz}$ and 18.90 $\mathrm{GHz}$. The direction of current is indicated by arrow sign. It is clearly observed from the current distribution display that the electric current strongly flows at the edge of the triangular slot, especially near the feeding probes of the patch. So, it can say that the slots dominate the antenna performance. Due to the triangular slot, the current flow is controlled which leads the lessening of the cross polarization level. At different parts of the patch, the current distribution is almost regular.

\section{Conclusion}

A new X shaped microstrip line feed patch antenna has been designed and presented in this work. The feeding technique, the adjusted slotted patch shape and the dimensions of the antenna is made it possible, to modify the acceptable reflection coefficient and characteristics of the radiation pattern in the expected frequency. The different parametric study, gain and radiation efficiency of the proposed antenna is also analyzed and discussed. For omnidirectional radiation pattern and high gain, the proposed triple band antenna can be a competitive solution for the current needs to be adopted with multi technology wireless devices in a $\mathrm{Ku} / \mathrm{K}$ band (satellite and radar) applications compare to other available dual band multi frequency antennas.

\section{References}

Alam, M. S., Islam, M. T., \& Misran, N. (2012). A novel compact split ring slotted electromagnetic bandgap structure for microstrip patch antenna performance enhancement. Progress in Electromagnetics Research, 130, 389-409.

Azim, R., Islam, M. T., Mandeep, J. S., \& Mobashsher, A. T. (2012). A planar circular ring ultra-wideband antenna with dual band-notched characteristics. Journal of Electromagnetic Waves and Applications, 26(14-15), 2022-2032. http://dx.doi.org/10.1080/09205071.2012.724189

Balanis, C. A. (2012). Antenna theory: analysis and design. Wiley-Interscience.

Chen, C., \& Yung, E. (2009). Dual-band dual-sense circularly-polarized CPW-fed slot antenna with two spiral slots loaded. Antennas and Propagation, IEEE Transactions on, 57(6), 1829-1833. http://dx.doi.org/10.1109/TAP.2009.2019990

Chen, Z., Ganjara, A. D., \& Chen, X. (2002). A dual-L antenna with a novel tuning technique for dual frequency applications. Antennas and Propagation, IEEE Transactions on, 50(3), 402-403. http://dx.doi.org/10.1109/8.999636

Eldewiny, M. A., Shams, S. I., \& Allam, A. (2010). A compact multiband planar antenna for DCS-1900/PCS/UMTS/WCDMA-2000/WLAN and WiMAX applications. Paper presented at the Microwave Conference Proceedings (APMC), 2010 Asia-Pacific.

Faruque, M. R. I., Islam, M. T., \& Misran, N. (2010). Evaluation of em absorption in human head with metamaterial attachment. Applied Computational Electromagnetics Society Journal, 25(12), 1097-1107.

Faruque, M. R. I., Islam, M. T., \& Misran, N. (2011). Electromagnetic (EM) absorption reduction in a muscle cube with metamaterial attachment. Medical Engineering and Physics, 33(5), 646-652. http://dx.doi.org/10.1016/j.medengphy.2010.12.004

Faruque, M. R. I., Islam, M. T., \& Misran, N. (2012). Design analysis of new metamaterial for EM absorption reduction. Progress in Electromagnetics Research, 124, 119-135. http://dx.doi.org/10.2528/PIER11112301

Garg, R. (2001). Microstrip antenna design handbook. Artech house publishers.

Habib Ullah, M., \& Islam, M. T. (2012). Design of a modified W-shaped patch antenna on Al $2 \mathrm{O} 3$ ceramic material substrate for Ku-Band. Chalcogenide Letters, 9(2), 61-66.

Islam, M. T., Mobashsher, A. T., \& Misran, N. (2010). A novel feeding technique for a dual band microstrip patch antenna. IEICE Transactions on Communications, E93-B(9), 2455-2457. http://dx.doi.org/10.1587/transcom.E93.B.2455

Pongchompoo, R., Santitewagul, V., \& Eungdamrong, D. (2009). A modified design of slot ring using E-shape. Paper presented at the Advanced Communication Technology, 2009. ICACT 2009. 11th International Conference on.

Rao, Q., \& Geyi, W. (2009). Compact multiband antenna for handheld devices. Antennas and Propagation, IEEE Transactions on, 57(10), 3337-3339. http://dx.doi.org/10.1109/TAP.2009.2029384 
Samsuzzaman, M., Islam, M. T., \& Mandeep, J. S. (2012). Design of a compact new shaped microstrip patch antenna for satellite application. Advances in Natural and Applied Sciences, 6(6), 898-903.

Samsuzzamana, M., Islamb, M. T., \& Faruqueb, M. R. I. (2013). Dual-band Multi Slot Patch Antenna for Wireless Applications. Journal of Telecommunications and Information Technology, 2, 19-23.

Shakib, M. N., Islam, M. T., \& Misran, N. (2010). High gain W-shaped microstrip patch antenna. IEICE Electronics Express, 7(20), 1546-1551. http://dx.doi.org/10.1587/elex.7.1546

Tiang, J. J., Islam, M. T., Misran, N., \& Mandeep, J. S. (2011). Slot loaded circular microstrip antenna with meandered slits. Journal of Electromagnetic Waves and Applications, 25(13), 1851-1862. http://dx.doi.org/10.1163/156939311797454042

\section{Copyrights}

Copyright for this article is retained by the author(s), with first publication rights granted to the journal.

This is an open-access article distributed under the terms and conditions of the Creative Commons Attribution license (http://creativecommons.org/licenses/by/3.0/). 